@ Entomologica Fennica. 7 July 1998

\title{
Intercalibration of different light-traps and bulbs used in moth monitoring in northern Europe
}

\author{
Reima Leinonen, Guy Söderman, Juhani Itämies, Seppo Rytkönen \& Ilpo Rutanen
}

Leinonen, R., Söderman, G., Itämies, J., Rytkönen, S. \& Rutanen, I. 1998: Intercalibration of different light-traps and bulbs used in moth monitoring in northern Europe. - Entomol. Fennica 9: 37-51.

Four different combinations of light-traps and bulbs were tested during the summer 1996 in Kainuu, northern Finland: a Jalas model with a 160-W (J/ $160 \mathrm{~W})$ blended light lamp or a $125-\mathrm{W}(\mathrm{J} / 125 \mathrm{~W})$ mercury vapour lamp, a Ryrholm trap with a $125-\mathrm{W}(\mathrm{R} / 125 \mathrm{~W})$ mercury vapour lamp and a Rothamsted trap with a $200-\mathrm{W}$ tungsten lamp (G/200W). The traps were rotated between four sites every night, but were kept in the same position for the fifth night in order to prevent the possible influence of moonlight. The longest distance between the traps was $150 \mathrm{~m}$, and there was no direct visibility between any of them. Three orders were inspected, i.e. Lepidoptera, Coleoptera and Hemiptera, the total numbers of individuals and species being as follows: $20857 /$ $425,862 / 101$ and $1868 / 58$. G/200W collected significantly fewer moths than the other traps. In some cases, J/125W collected significantly more moths and less species than the $\mathrm{J} / 160 \mathrm{~W}$ design. The $\mathrm{R} / 125 \mathrm{~W}$ design collected significantly more species than the J/160W design. Similar differences in the effectiveness of the lamps and traps were found in the case of Coleoptera and Hemiptera. Alpha diversities showed the same trend.

Reima Leinonen, Kainuu Regional Environment Centre, P.O. Box 115, FIN87101 Kajaani, Finland

Guy Söderman, Finnish Environment Institute, P.O. Box 140, FIN-00251 Helsinki, Finland

Juhani Itämies, Zoological Museum, P.O. Box 333, FIN-90571 Oulu, Finland Seppo Rytkönen, Department of Biology, P.O. Box 333, FIN-90571 Oulu, Finland

Ilpo Rutanen, Kansankatu 25 as. 6, FIN-05900 Hyvinkää, Finland

Received 26 November 1997, accepted 16 February 1998

\section{Introduction}

The monitoring of moths underwent a revolution about 50 years ago, when the technique of lighttrapping was introduced. The longest time series based on the same trap design are from England (Williams 1948, Taylor \& French 1974), where Rothamsted traps with a clear 200-W tungsten lamp bulb have been used since the year 1933. In Finland, lepidopterologists have used almost sole- 
ly Jalas traps (Jalas 1960,1969) with a variety of different bulb types, ranging from 160 -W blended lamps to 500-W mercury vapour lamps. Comparisons between trap designs and bulbs have been performed by Williams (1951), Taylor and Brown (1972), Mikkola (1972), Blomberg et al. (1976), Ahola (1981-1983, pers.comm.), Bruun (1985) and Marttila (1988). In these comparisons, the effect of different bulbs and wavelengths upon the captures have been the target of research. However, these studies have been made in areas with different nightly illumination conditions, which is why they still leave many questions unanswered.

In the Finnish moth monitoring programme, which was started in 1993, Jalas traps with blended 160-W lamp bulbs have been a standard (Väisänen 1993). A few private persons who have joined the monitoring network using their own traps have preferred to continue using 125 -W mercury vapour lamps. When the moth monitoring programmes of the Baltic states and western Russia were started in 1995, the Finnish trap design standard was adopted into use there. National programmes were simultaneously developed for the other Nordic countries, viz. Denmark and Iceland in 1995 and Sweden in 1996. In these countries, another trap design was preferred, namely the Ryrholm trap with a 125 -W mercury vapour lamp bulb (Söderman 1994, Nieminen 1996). The use of different trap designs and bulbs in different parts of northern Europe made it necessary to study the effects of the technical designs upon the captures.

The aim of this study was to compare the traps and bulbs used in different moth monitoring projects in Fennoscandia and Great Britain. If there are relevant differences, there will be a definite need to find suitable correction coefficients for the data before any joint reporting can be achieved.

\section{Material and methods}

\subsection{Selected trap designs}

The trap designs tested were those of relevance for the northern European moth monitoring programmes (Söderman 1994).

1. Jalas trap with a $160-\mathrm{W}$ blended lamp bulb (model Philips/white) - abbreviated as J/160W below. The trap is of hanging design and its lamp is situated ca. $1 \mathrm{~m}$ above the ground level, from where the light spreads sidewards and obliquely downwards. The upward spread of light is less effective due to its rain-sheltering roof (Fig. 2b). Being mainly constructed of flexible plastic, this trap is light-weight, portable and the least expensive of the traps compared.

2. Ryrholm trap with a $125-\mathrm{W}$ mercury vapour lamp (model Philips/white) - abbreviated as R/125W. The trap is a ground-based design, and the lamp bulb is ca. $0.3 \mathrm{~m}$ above the ground level, from where its light spreads effectively up- and sidewards, but less so downwards (Fig. 2a).

3. Jalas trap with a $125-\mathrm{W}$ mercury vapour lamp (model Philips/white) - abbreviated as J/125W. The design is similar to $\mathrm{J} / 160 \mathrm{~W}$, but the lamp type is regarded as more effective.

4. Rothamsted trap with a clear $200-\mathrm{W}$ tungsten lamp abbreviated as G/200W. This trap stands on its own podium and the light bulb is situated ca. $1.5 \mathrm{~m}$ above the ground level. The light spreads well to the sides and upwards, but poorly to the ground level (Fig. 3a). The funnel is much smaller than in the other designs.

A paired test including two trap designs, G/200W and $\mathrm{J} / 160 \mathrm{~W}$, was performed during weeks $25-42$ in 1996 at a nearby site in Viiksimo $\left(64^{\circ} 15^{\prime} \mathrm{N}-30^{\circ} 23^{\circ} \mathrm{E}\right)$ (R. Leinonen, unpubl.). Further south in Finland, at the Lammi Biological Station $\left(61^{\circ} 03^{\top} \mathrm{N}-25^{\circ} 02^{\prime} \mathrm{E}\right)$ in the Southern Boreal Region, comparisons between $\mathrm{G} / 200 \mathrm{~W}$ and $\mathrm{J} / 160 \mathrm{~W}$ have been performed since 1993 (Woiwood \& Riley 1996).

\subsection{Test area and subsites}

The intercalibration test area was established in the yard of the Kainuu Regional Environment Centre, in a suburban area of Kajaani (Grid $27^{\circ} \mathrm{E} 7126: 536$ ). Biogeographically, the place belongs to the Middle Boreal Region (called western taiga) of Europe $\left(64^{\circ} 12^{\mathrm{N}} \mathrm{N}-27^{\circ} 46^{\prime} \mathrm{E}\right)$. The site was selected for three reasons. Firstly, the day-to-day operations, i.e. the emptying and rotation of the traps was easy, secondly, the area was fenced (preventing possible interference), and thirdly, the effective trapping season was relatively short and no enormous amount of insects was expected to pile up for identification. The general outline of the test area and its subsites are shown in Fig. 1. The traps were placed so that there was no direct visibility between them.

Subsite 1 represented an ecotone between a Bilberry (Vaccinium myrtillus) spruce forest and a garden lawn with a few ornamental scrubs (Fig. 2a).

Subsite 2 represented a fresh Scots pine forest. Immediately south of it grew secondary willow and birch scrub on an old cutting, which was flooded by heavy rains in spring (Fig. 2b).

Subsite 3 represented a Cowberry (Vaccinium vitisidaea) pine forest that had been cut some ten years previously. To the west and east of it there were areas of ruderal plant communities (Fig. 3a). 
Fig. 1. General outline of the test area and location of the different subsites (1-4).

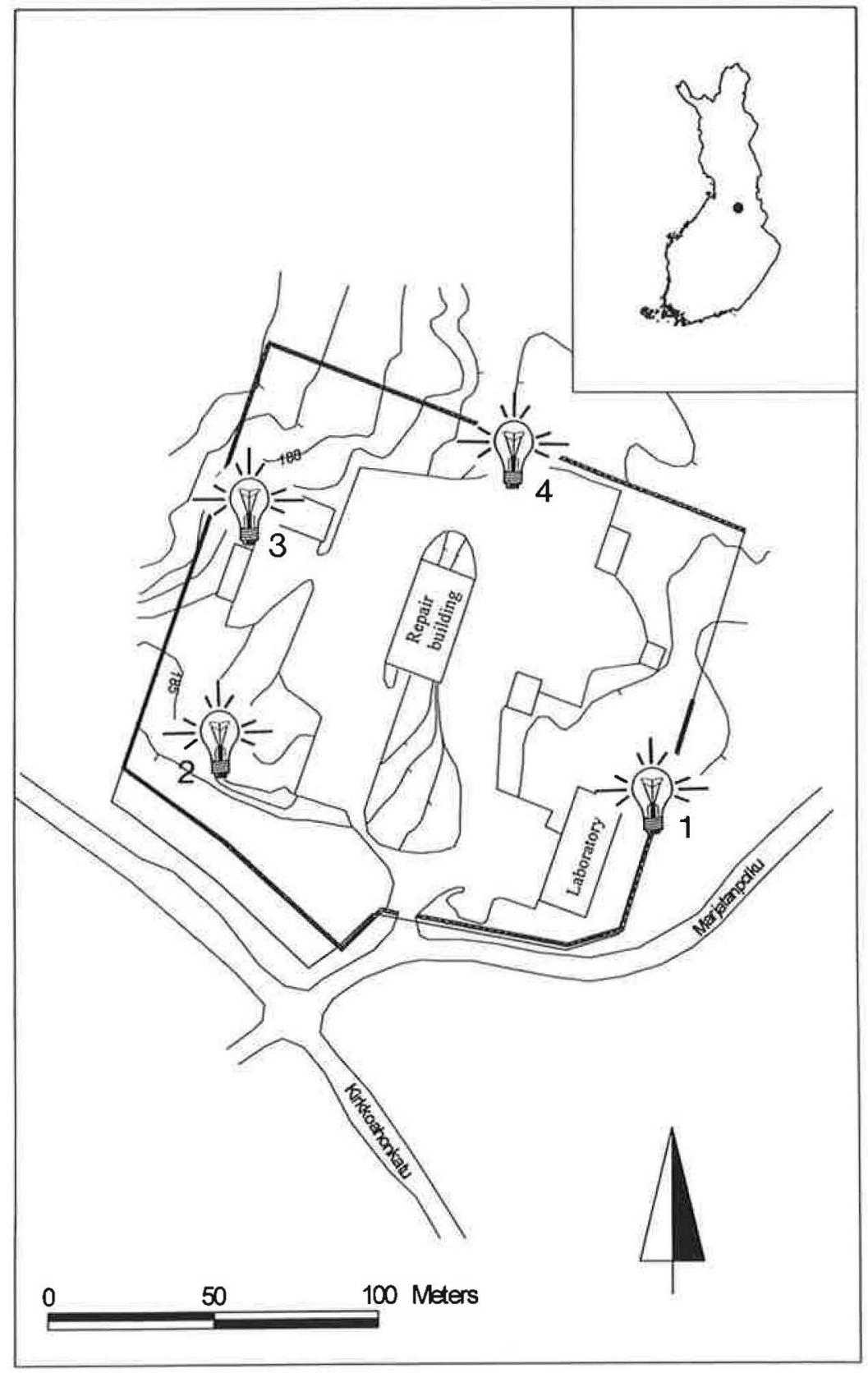

Subsite 4 represented an ecotone between ruderal plant communities and a forest cutting with secondary growth of willows and birch scrub. North of this was a clearing with graminaceous cover (Fig. 3b).

The most shaded subsite was no. 2 and the most open site no. 3. The subsite habitat descriptions were based on vegetation inventories made in late August in the same year.

\subsection{Operation}

The intercalibration test was started on 1 May 1996, and it lasted five months, ending on 30 September. The traps were emptied every morning and moved clockwise to new positions. Every fifth night they were kept at the same subsite for two successive nights, in order to avoid any influence of the lunar cycle (28 days). 

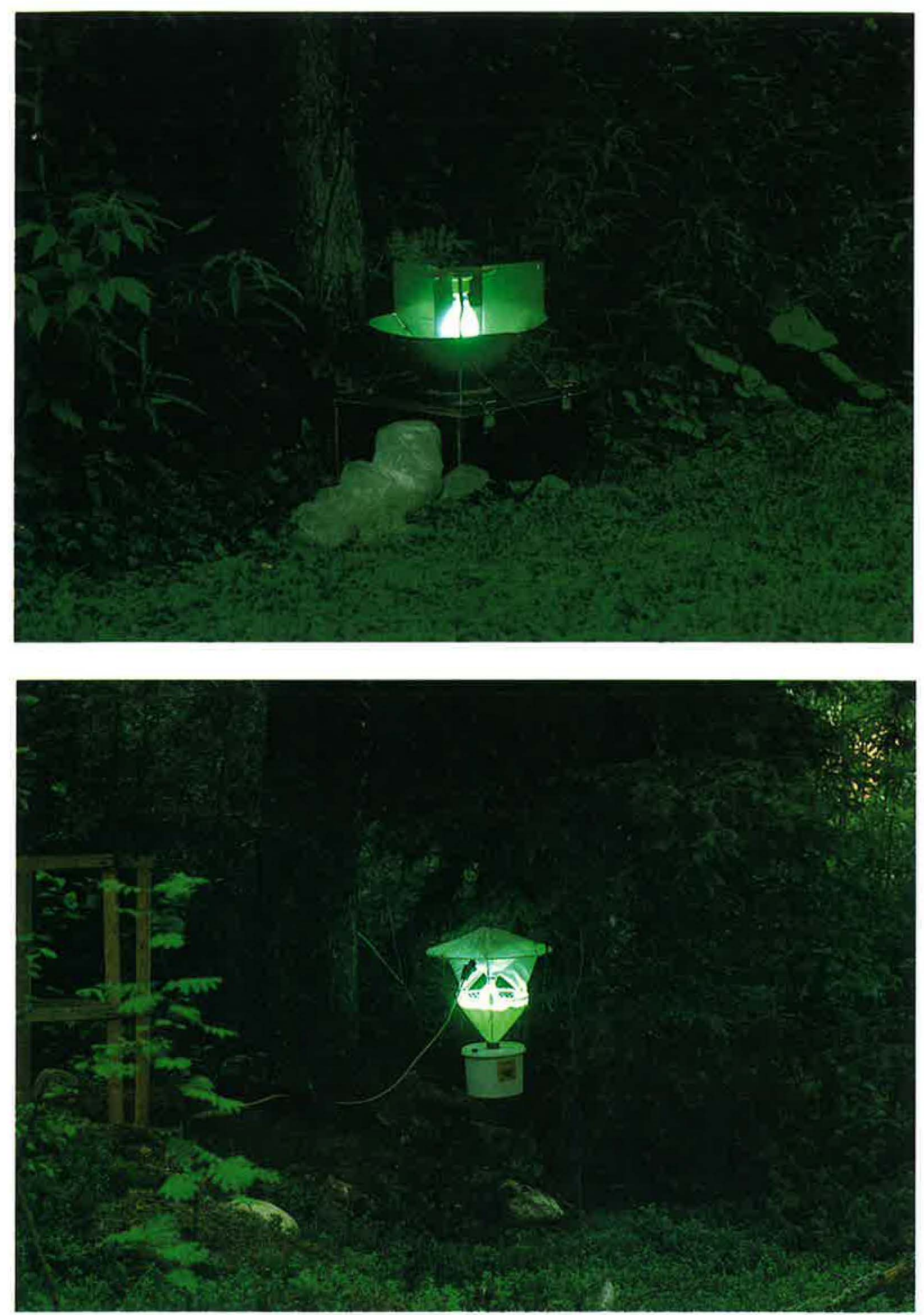

Fig. 2. General view of the subsites used in the intercalibration test of four traps in May-September 1996. A. Subsite 1 with a Ryrholm trap (R/125). B. Subsite 2 with a Jalas trap $(\mathrm{J} / 125)$. 

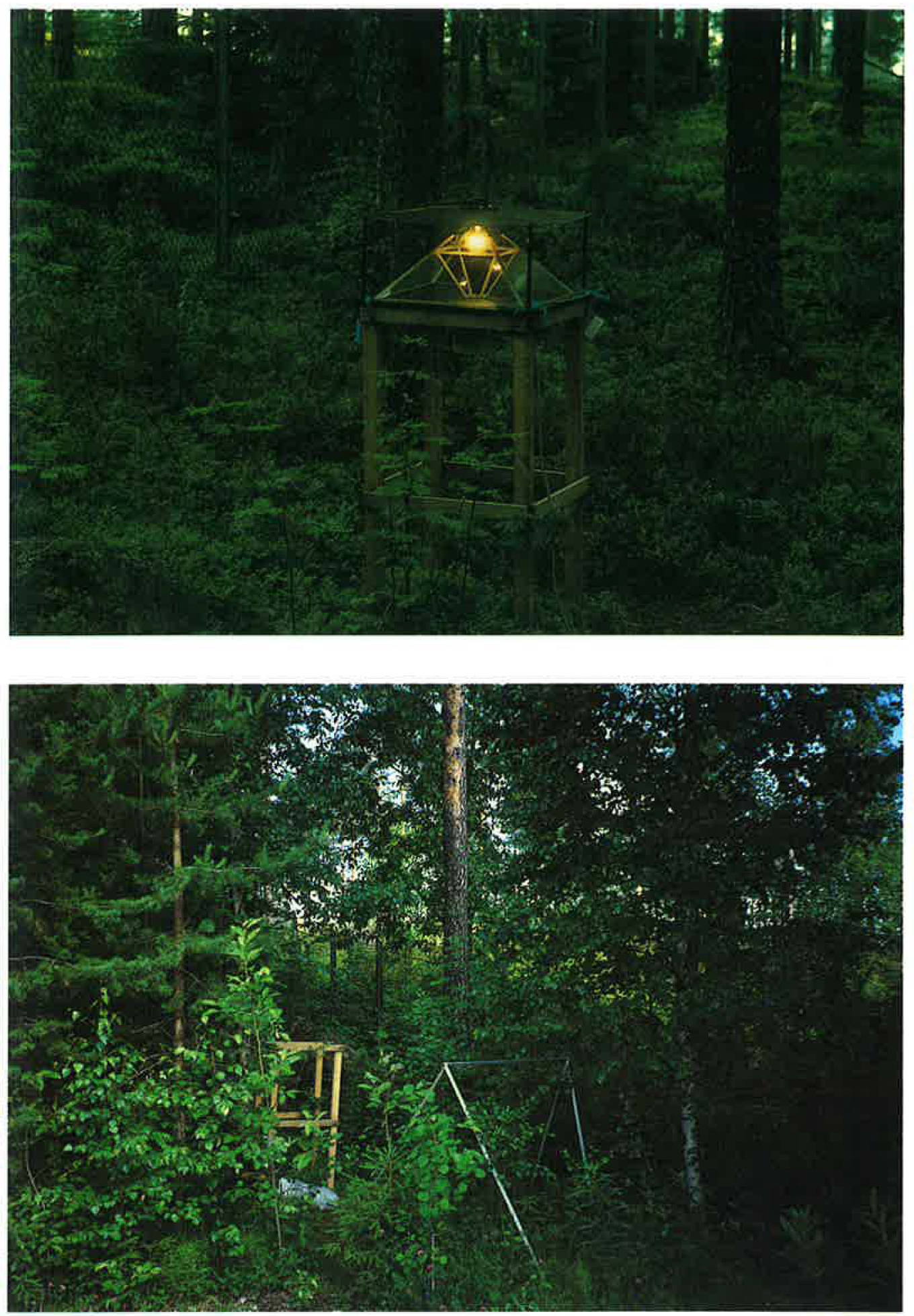

Fig. 3. General view of the subsites used in the intercalibration test of four traps in May-September 1996. A. Subsite 3 with a Rothampsted trap (G/200). B. Subsite 4. 
The light bulbs were kept lit between 18.00 and 06.00 hours with the aid of a timer. Electricity was supplied centrally with surface cables. Special plastic rain shelters were used for the choke and plugs of R/125W, whereas the other trap designs had roofs to shelter the electrical connections. The test succeeded well, and only 2 night captures from two traps were lost due to lightning. Tetrachlorethane was used as a killing agent. The samples were put in a freezer until sorted and identified. The moth material is kept in the Zoological Museum of the University of Oulu as population samples. The species lists of Lepidoptera, Coleoptera and Hemiptera are preserved in the Zoological Museum of Oulu and are available upon request.

\subsection{Local weather conditions}

The summer of 1996 was not normal (Anon. 1996). Heavy rains in the early summer reduced moth activity, which became normal or even slightly better than normal at the end of August. When the nights became cool in September, the captures were smaller, and towards the end of this month only a few individuals per night were captured.

The daily mean temperature exceeded zero degrees centigrade when the test started and the $+10^{\circ}$-limit, which is regarded as the beginning of summer, was reached for the first time as early as 10 May, but continuously only from the beginning of June. The highest mean temperatures were measured just after mid-August and the end of the vegetative period coincided with the beginning of September. The effective temperature sum $\left(\mathrm{t} 7^{\circ} \mathrm{C}\right)$ started to rise slowly in May and reached its final sum $\left(680^{\circ} \mathrm{C}\right)$ at the end of $\mathrm{Au}-$ gust.

The heaviest rains fell between 15 June and 15 July, when the daily amount of $20 \mathrm{~mm}$ was exceeded on three successive days. Long dry periods occurred in August. Daily precipitation correlated negatively with the daily moth captures.

\subsection{Statistical analyses}

In analysing the catch data, catch per night was used as a sample unit. The data were strongly skewed to the right, and non-parametric tests were therefore used. The differences between the traps were analysed with KolmogorovSmirnov two-sample tests. Six pairwise tests were performed for "microlepidoptera", "macrolepidoptera" and the combined moth data of each month. The sequential Bonferroni method was applied to assess significant differences (at a significance level of $\alpha=0.05$ ) in these pairwise analyses (Sokal \& Rohlf 1995).

The species number data were used to analyse the cumulative number of species collected with the different trap designs at the different sites. The sites served as replicates. Every fifth night the traps were kept at the same site for two successive nights. These second nights were excluded from this analysis. The differences between the traps and the sites were analysed by using ANOVA and Tukey's HSD a posteriori tests.

Multidimensional scaling (MDS) was used to assess the differences and temporal changes in species composition in the catches of the different traps. Distance matrices were calculated from the frequency data by using the SPSS phi-square dissimilarity measure option. The dissimilarity measure is based on the chi-square statistics (see SPSS version 6.1.3.).

The $\alpha$-diversity index, calculated as $S=\alpha \log (1+N /$ $\alpha$ ), has two driving variables: the number of species (S) and the number of individuals (N) (see e.g. Kempton \& Taylor 1974).

To determine the possible need for a correction coefficient, trap $\mathrm{J} / 160$ was used as a control trap. An additional reason for the selection of this trap is the fact that it is the design most widely used for moth monitoring in the Nordic countries (Nieminen 1996). The results of the other three traps were compared with $\mathrm{J} / 160$ by percent age deviaton (Table 1).

Table 1. The total catches of insect groups by the traps (see Material and methods). The percentage column on the right site of the trap indicates the percentage deviation from the $\mathrm{J} / 160$ trap = the control trap.

\begin{tabular}{lrrrrrrrr}
\hline & $\mathrm{J} / 160$ & $\mathrm{R} / 125$ & $\%$ & $\mathrm{~J} / 125$ & $\%$ & $\mathrm{G} / 200$ & $\%$ & Total \\
\hline Microlepidoptera species & 183 & 200 & 109 & 191 & 104 & 119 & 65 & 255 \\
Macrolepidoptera species & 123 & 149 & 121 & 133 & 108 & 75 & 61 & 170 \\
Hemiptera species & 36 & 35 & 97 & 35 & 97 & 30 & 83 & 57 \\
Coleoptera species & 31 & 76 & 245 & 41 & 132 & 12 & 39 & 101 \\
$\quad$ Total species & 373 & 460 & 123 & 400 & 107 & 236 & 63 & 583 \\
Microlepidoptera individuals & 2357 & 3600 & 153 & 3052 & 129 & 786 & 33 & 9795 \\
Macrolepidoptera individuals & 2451 & 4426 & 181 & 3065 & 125 & 1120 & 46 & 11062 \\
Hemiptera individuals & 475 & 567 & 119 & 565 & 119 & 261 & 55 & 1868 \\
Coleoptera individuals & 122 & 440 & 361 & 256 & 210 & 44 & 36 & 862 \\
$\quad$ Total individuals & 5405 & 9033 & 167 & 6938 & 128 & 2211 & 41 & 23587 \\
\hline
\end{tabular}


Fig. 4. Distribution of fresh insect biomass between the different trap designs (see Methods).

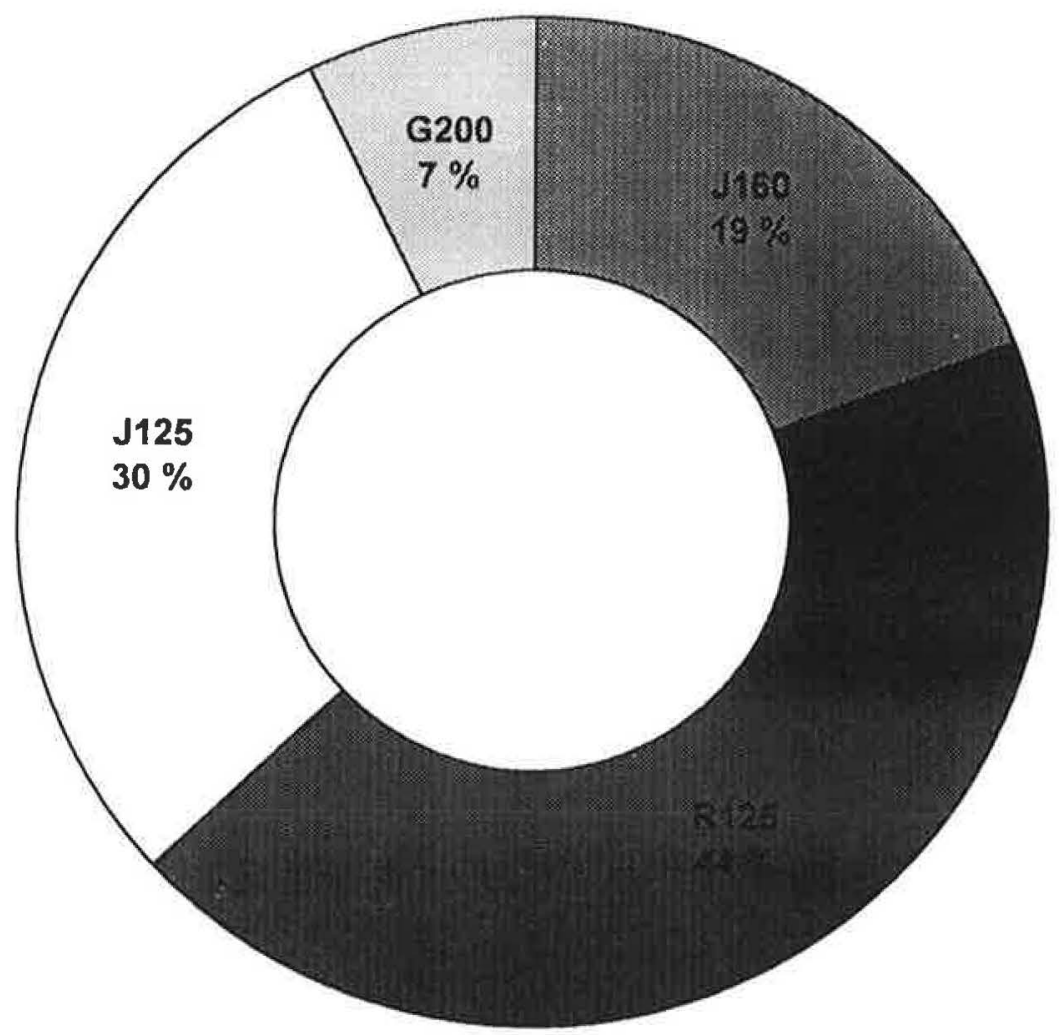

\section{Results}

Three orders, i.e. moths (Lepidoptera), bugs (Hemiptera) and beetles (Coleoptera), were sorted out and identified down to species level. The total numbers of species and individuals were as follows: $20857 / 425,1868 / 58$ and $862 / 101$. There was large variation in the catch of species and individuals between certain traps (Table 1), while the differences between some designs were minimal. $\mathrm{R} / 200$ differed most strikingly from the other traps in all the studied groups. The superiority of $\mathrm{R} /$ 125 was most obvious in the case of beetles, of which two and half times more species and three and half times more individuals were caught with this trap than trap $J / 160$. This was not due to the different lamp type, because $\mathrm{J} / 125$ was only slightly better than $J / 160$ in the case of beetles.

The total insect mass captured weighed $603 \mathrm{~g}$. The percentage distribution between the different trap designs is shown in Fig. 4. The moths constituted over $90 \%$ of this mass. The greatest bulk $(63 \%)$ was captured in August, and the daily maxi- mum was recorded on the night of 21-22 August, when altogether 983 individuals (macro- and microlepidoptera) were captured.

\subsection{Species compositions}

\subsubsection{Moths (Lepidoptera)}

A total of 20857 moth individuals of 425 species were recorded. Of these, 9795 individuals and 255 species can be classified as "microlepidoptera" and 11062 individuals and 170 species as "macrolepidoptera". The species recorded were typical of the Middle Boreal Region, except two, Ipimorpha subtusa and Chionodes fumatella, which were new to the Kainuu biogeographical province. No clear habitat preference in the captures of the different trap designs could be observed. The most abundant species were Eulithis populata (1 470 ind.), Chloroclysta citrata (1 257 ind.), Eupithecia pusillata (1 324 ind.) (all belonging to Geometridae), Zeiraphera ratzeburgiana 


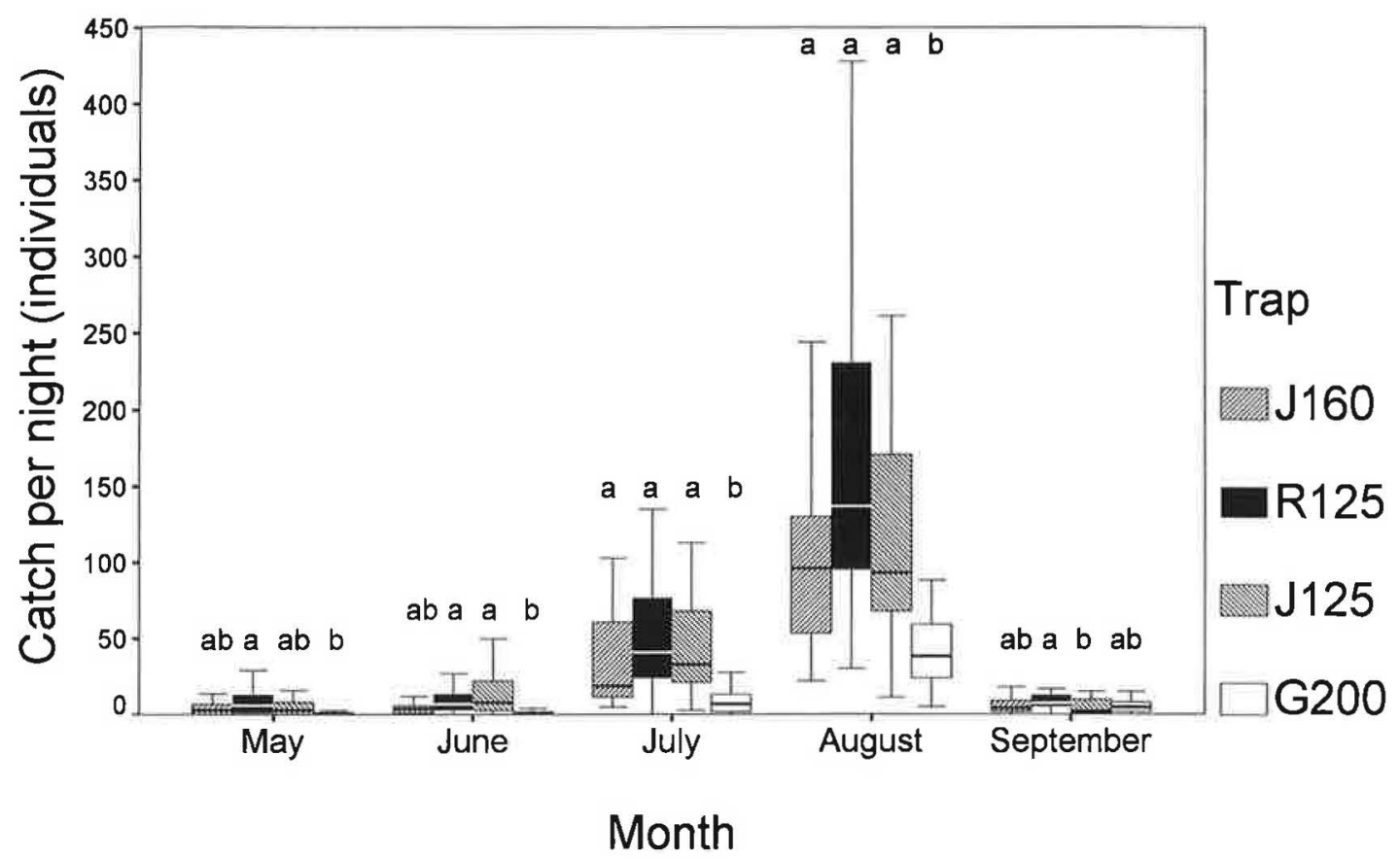

Fig. 5. Box plots of average monthly per-night catches of Lepidoptera by four different traps during MaySeptember 1996. The letters above the boxes indicate significant (at level $\alpha=0.05$ ) differences in within-month catches between the traps (for analysis, see Methods). The "boxes" contain the $50 \%$ of values falling between the 25th and 75th percentiles, and the "whiskers" the highest and lowest values, excluding outliers (i.e. values over 1.5 times the box-length from the upper and lower edge of the box, see SPSS).

(987 ind.) and Rhopobota naevana (578 ind.) (Tortricidae).

Figs. 5-7 show the average nightly catches of all moth individuals, including "microlepidoptera" and "macrolepidoptera", in May to September. Two general findings can be seen: 1) In 7 cases of 11 monthly comparisons, which revealed significant differences between the traps (KolmogorovSmirnov two-sample tests and a posteriori testing with the sequential Bonferroni method at a significance level of $\alpha=0.05$, see Material and methods), the G/200W design collected significantly fewer moths than any other trap; and 2) Whenever the other three traps differed from each other, the J/160W design collected significantly fewer "macrolepidoptera" than either the R/125W (August) or the $\mathrm{J} / 125 \mathrm{~W}$ design (June).

The cumulative numbers of moths caught by the different trap designs during the season are shown in Fig. 8. During the whole season, the G/200W design collected significantly fewer moths than the other designs in all data sets ("microlepidoptera", "macrolepidoptera", all moths)
(Kolmogorov-Smirnov two-sample tests, and a posteriori testing with the sequential Bonferroni method at a significance level of $\alpha=0.05$, see Material and methods). In addition, the R/125W design caught significantly more "microlepidoptera" than J/160W. On the other hand, the average catches of individual "microlepidoptera", "macrolepidoptera" and all moths by J/160W and $\mathrm{J} / 125 \mathrm{~W}$ did not differ between the four sites (Kolmogorov-Smirnov two-sample tests, in all the six pairwise tests $\mathrm{z}<0.97, \mathrm{p}>0.30$ ).

The cumulative numbers of species collected with the different trap designs during the season are presented in Fig. 9. Two-way ANOVA showed that the sites did not differ $\left(F_{3,9}=0.65, p=0.601\right)$, but the traps differed highly significantly $\left(\mathrm{F}_{3,9}=\right.$ $63.99, p<0.001)$ in the number of species recorded during the season. Tukey's HSD a posteriori analysis (at a significance level of $\alpha=0.05$ ) showed that the G/200W design caught significantly fewer species than the others. In addition, the $\mathrm{R} / 125 \mathrm{~W}$ design collected significantly more species than the $\mathrm{J} / 160 \mathrm{~W}$. 


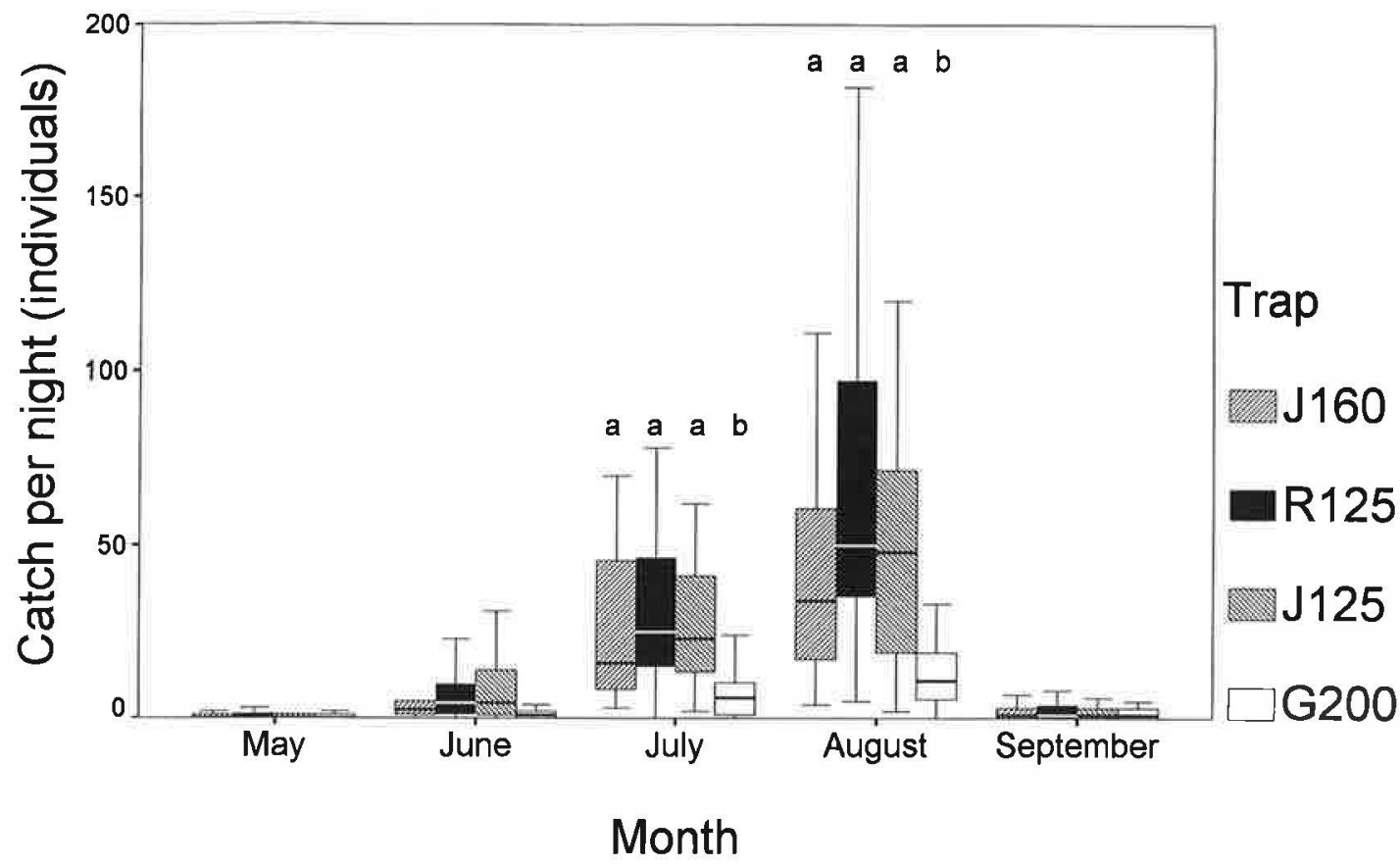

Fig. 6. Box-plots of monthly per-night catches of Microlepidoptera by four different traps during MaySeptember 1996. For details, see Fig. 5.

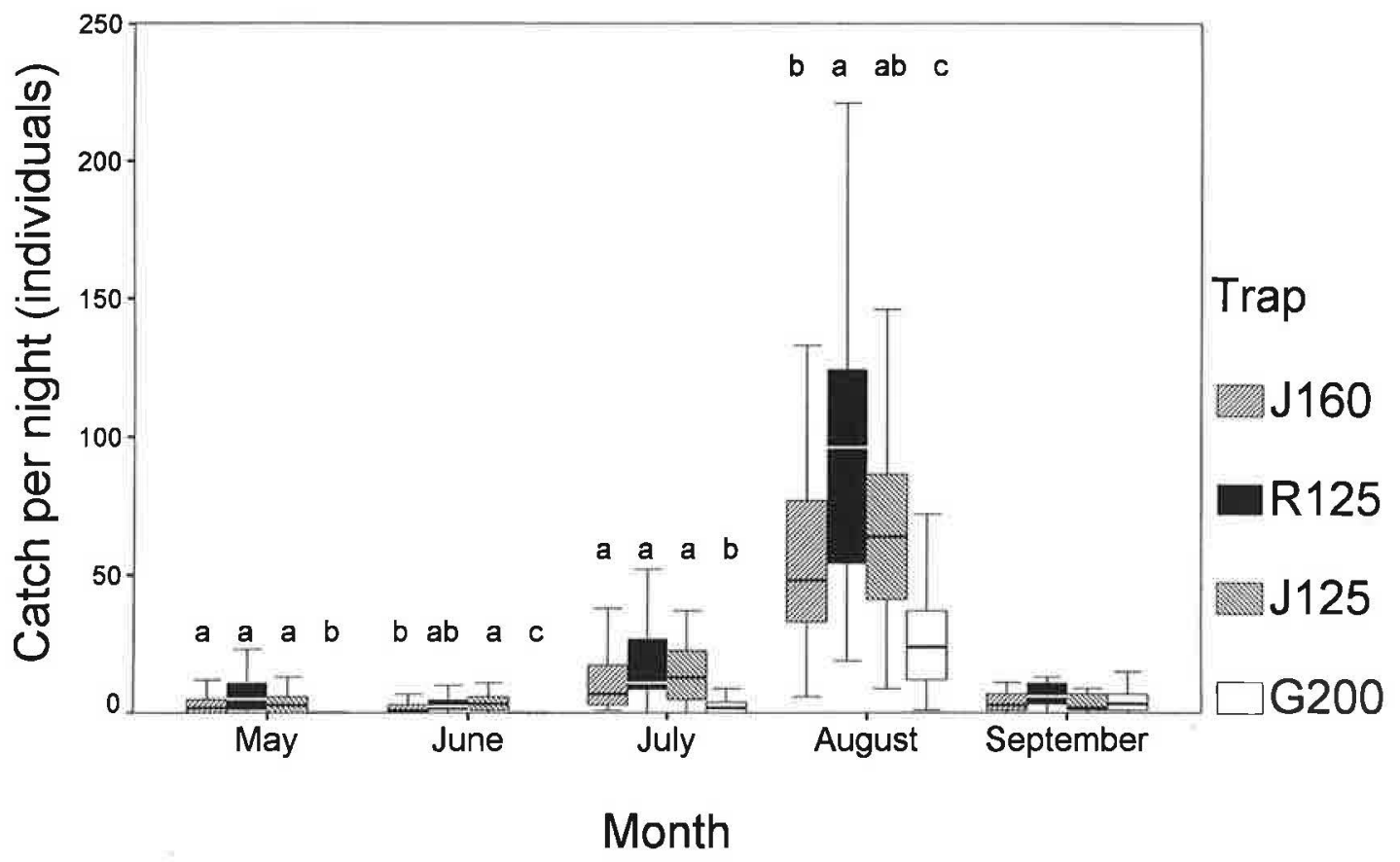

Fig. 7. Box plots of monthly per-night catches of Macrolepidoptera by four different traps during MaySeptember 1996. For details, see Fig. 5. 

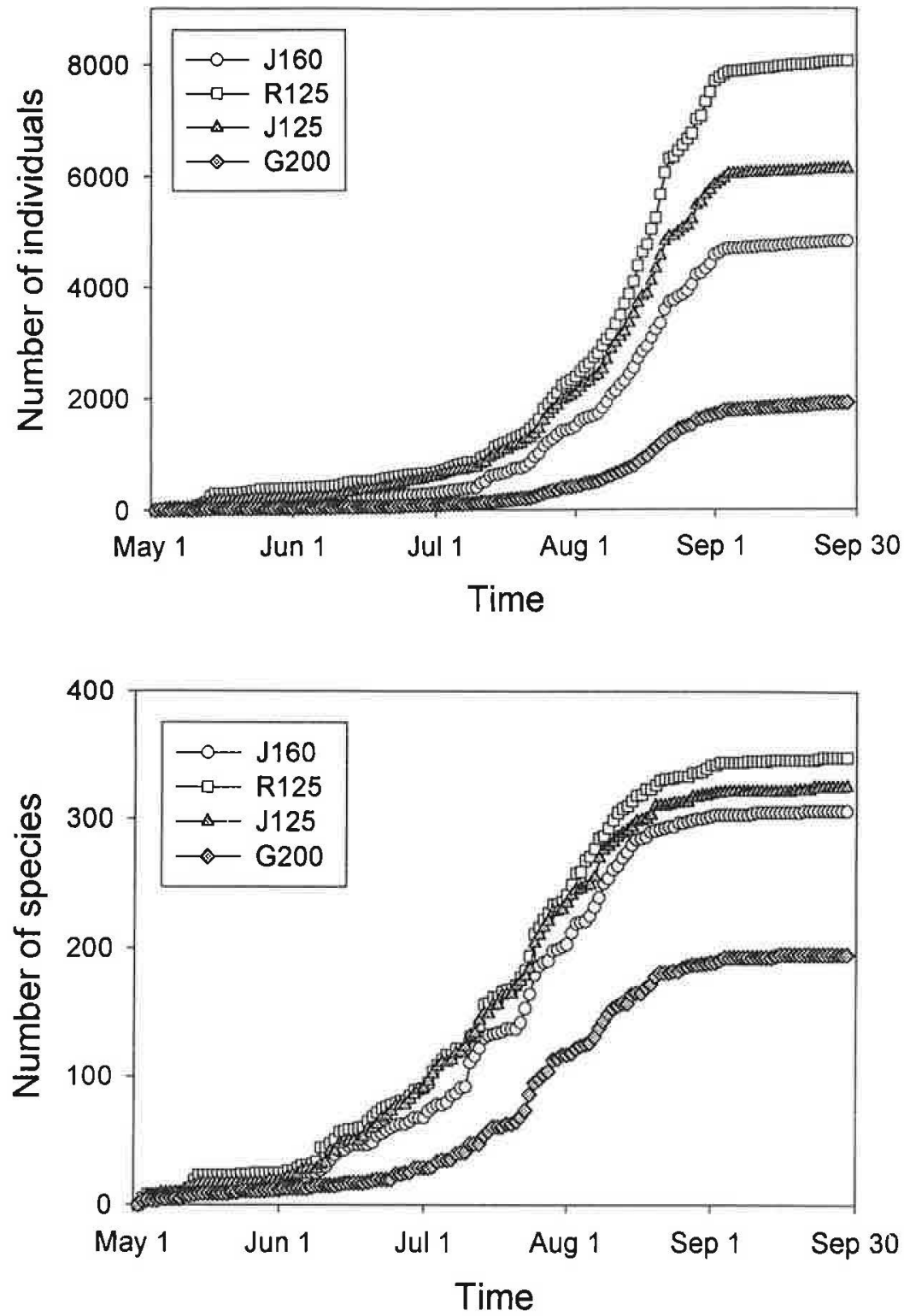

Fig. 8. Cumulative number of Lepidoptera individuals caught by four different traps during May-September 1996.
Fig. 9. Cumulative number of Lepidoptera species caught by four different traps during May-September 1996.
The species composition in the monthly catches changed greatly during the course of the season, but the variation attributable to different trap designs remained low, as revealed by the MDS analyses (Stress $=0.1985, \mathrm{RSQ}=0.89$ ). On the other hand, the G/200W design seemed to deviate from the others in June, July and August, indicating differential catchability of moths.

When the total species numbers are surveyed on a monthly basis (Fig. 10), it appears that the difference between the effectiveness levels of the traps was smallest in the spring and autumn, when the total number of species is also at its lowest. Exceptions from this "rule" are the slender and poorly flying species of Geometridae, which also seem to enter trap 4 ( $\mathrm{R} 200$ ), especially in autumn. The northern study site might explain this, because the tungsten bulb does not emit UV wavelenghts, which are probably needed in the nights much lighter than in England. Towards the autumn the nights get darker, thus improving the catching capacity of this trap design. 
Fig. 10. Number of Lepidoptera species caught by four different traps during May-September 1996.

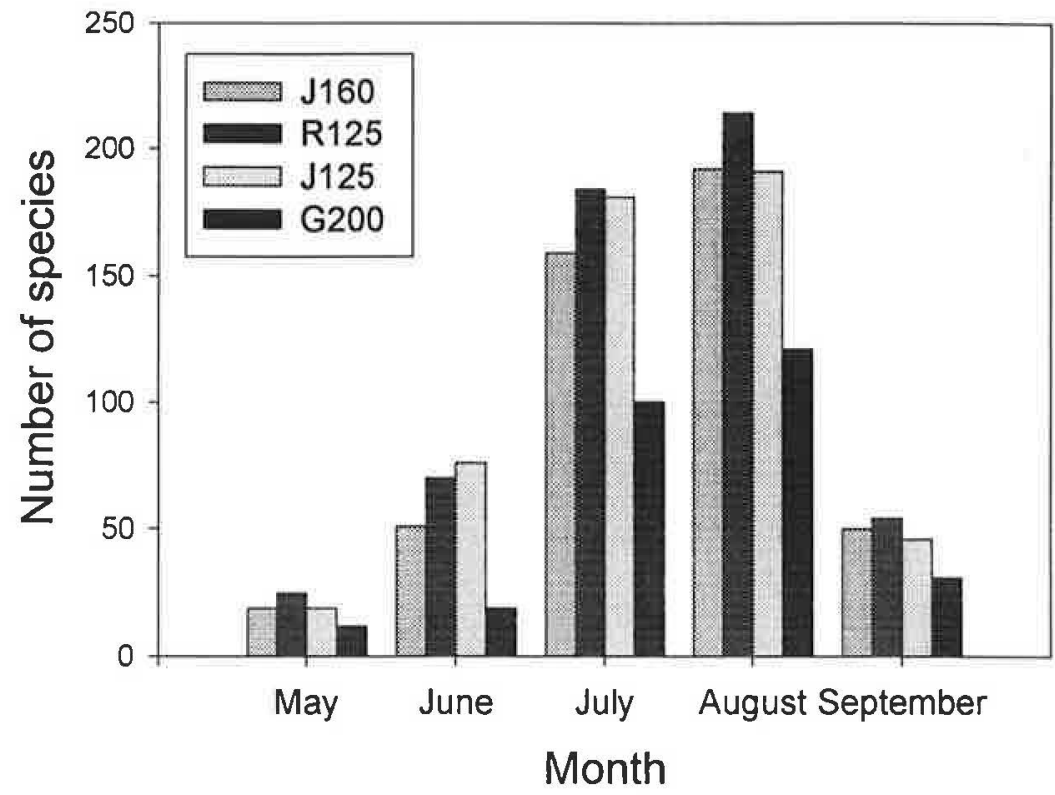

On the other hand, $\mathrm{R} / 125 \mathrm{~W}$ appears to be the most effective design. This is partly due to the more effective spread of light and the low position of the bulb. The only problem with this trap design is its openness. If the trap is sampled once a week, falling autumn leaves may easily block the funnel and prohibit moths from entering the trap. This could be avoided by daily sampling and daily cleaning of the funnel. In addition, sampling was felt to be tedious, as the sample container consists of a large plywood box that cannot be detached from the trap proper (but this has nothing to do with the effectiveness of the design itself). The superior effectiveness of trap 2 (R 125) persisted throughout the summer and between the trap sites, too.

When the results of the subsites are compared irrespective of the trap designs used, no remarkable differences can be found. Each subsite presented 19-25 species only captured at that spot, but most of these were recorded in single numbers and thus occurred randomly.

\subsubsection{Bugs (Hemiptera)}

All individuals of leafhoppers (Homoptera, Auchenorrhynca) and true bugs (Heteroptera) captured in the light-traps were identified to the spe- cies level, with the exception of two leafhopper females. The total number captured was 1868 individuals, of which $75 \%$ were leafhoppers (1 392 individuals) and the rest true bugs. These individuals belonged to 58 species, of which half were leafhoppers and half true bugs. Of the recorded species, 29 are tree-living, while 7 live on brush, 18 in the herbaceous layer and 4 on the ground. The corresponding individual numbers were 1428 tree-living, 41 living on brush, 350 in the herbaceous layer and 49 on the ground. This ratio, which emphasizes the species living on trees and herbs, is typical of light-attracted Hemiptera captures. It differs from the habitat preferences within the whole systematic group, where herbliving species dominate, being followed by ground-living species.

The number of species in each trap type differed insignificantly, being 35-36 species for all the other trap types except G/200W, which captured 30 species. The captured number of individuals shows a similar tendency, being 475-567 individuals for the Nordic trap designs, but only 261 individuals for the Rothamsted trap.

Altogether 23 species were recorded in all the four trap types. Of these species, $48 \%$ are treeliving, whereas each of the other habitat groups accounted for $25-29 \%$. The species captured in only one trap type number 27 , of which $34 \%$ are 
tree-living, 57-59\% brush- and herb-living and 75\% ground-living. These 3 ground-living species belong to the family Lygaeidae and were captured only with R/125W, which has the most extensive contact with the ground level.

Some preferences to trap designs and light bulbs could be noted: Populicerus laminatus (77\% in R/125W), Macustus grisescens (67\% of these leafhoppers living close to the ground in $\mathrm{R} / 125 \mathrm{~W}$ ), Alnetoidia alneti (63\% preferred blended light), Linnavuoriana sexmaculata $(79 \%$ preferred blended light), Linnavuoriana decempunctata ( $87 \%$ caught by MV lamps), Empoasca smaragdula ( $85 \%$ preferred blended light), Lygocoris contaminatus ( $43 \%$ caught by G/200W), Empoasca vitis (76\% in Jalas traps), Empoasca kontkaneni (61\% in Jalas traps).

It was surprising that no aquatic bugs were captured, although they are generally attracted by light quite far from their habitats. Faunistically, several interesting records were made: four true bugs, i.e. Lygus rhamnicola, Lygocoris viridis, Phytocoris longipennis and Plagiognathus albipennis, have not been reported to occur in the province of Kainuu (cf. Lammes \& Rinne 1990). Of the leafhoppers, 20 species were new to the region (cf. Ossiannilsson 1984), but this region has been poorly surveyed with regard to leafhoppers.

\subsubsection{Beetles (Coleoptera)}

A total of 862 individuals of beetles belonging to 101 species were captured in the traps. Thirtyfive were ground-dwellers: predators or myco- or saprophages, 34 species were saproxylics, living and developing in dead and decaying trunks, stumps or branches of trees either as xylo- or mycophages or as predators, while 26 were brushand herb-living phytophages or predators. Six aquatic species were recorded.

The most common group consisted of soldier and sailor beetles (Cantharidae) and the commonest species was Rhizophagus ferrugineus (Rhizophagidae), of which 403 individuals were counted, accounting for approximately half of all the beetles captured. The trap distribution was: J/160: 31 species/122 individuals, J/125: 41/256, R/125: 76/440, G/200: 12/44.
As regards the individual numbers of the 862 specimens captured, 102 of them were ground dwellers, 17 aquatic, 501 saproxylic and 242 brush and herb dwellers. Thus, more than half (58\%) of the individuals caught were tree-living species, which depend on the high abundance of one species, Rhizophagus ferrugineus, which is a predator of bark beetles, living subcortically on dead trunks of conifers.

The most effective trap type in view of the number of both species and individuals was the Ryrholm model with a 125 -W mercury vapor lamp (R 125). This trap captured 76 species and 440 individuals. One argument for this might be the location of the trap quite near to the ground. Most of the ground-dwelling and also of the saproxylic beetles living on dead logs are poor flyers and do not rise very high in the air during their flight. Twenty-seven (77\%) of the 35 ground-living species, and $29(85 \%)$ of the 34 saproxylic species were captured with this trap model. The Rothamsted trap with a $200-W$ tungsten lamp (G/200), on the other hand, captured significantly fewer species (12) and individuals (44), most of them being light-weight soldier and sailor beetles very common and abundant in brush and herb vegetation, such as species of the family Cantharidae. Five of the only six species found in all types of traps also belong to this systematic group. Sixtythree species were only captured by one trap type and, of these, 46 only by the Ryrholm trap (R/125).

Of the most abundantly recorded systematic group, Cantharidae (218 ind.), 88 individuals $(40 \%)$ were captured in the Jalas model trap with a mercury vapour lamp (J/125). There were, however, no significant differences between the trap types in the capture of Cantharidae. Of the most abundantly recorded species, Rhizophagus ferrugineus (403 ind.), 246 individuals (61\%) were captured in the Ryrholm trap with a mercury vapour lamp (R/125).

Some rare species new to the Kainuu region (Lindroth 1960) were noted, such as Leiodes lucens and Leiodes fracta (Leiodidae), which develop in subterraneous mycorrhiza, Deleaster dichrous (Staphylinidae), a predaceous groundliving species, Stagetus borealis (Anobiidae), a saproxylic species developing in bracket fungi, Thalycra fervida (Nitidulidae), which develops in soil-dwelling fungi, and Cryptophagus corticinus 
(Cryptophagidae), which lives subcortically on dead trunks and prefers burned forests.

\subsection{Alpha index calculations}

Alpha diversity is an expedient way to measure biodiversity in a small-scale inventory (Kouki 1994). It has been used in moth monitoring programmes to explain differences between regions, habitats and consecutive years (Taylor et al. 1976, Söderman 1996, Woiwood \& Riley 1996).

The alpha indices for the different groups identified are shown in Table 2. The lower values for G/200W stand out, with the exception of Hemiptera. The differences between the other traps are quite insignificant, with the exception of R/125W in the case of Coleoptera. This ground-based design apparently collects more ground-dwelling insects, which was also the case with true bugs.

When the different subsites were compared (Table 3), no significant differences were found in the number of captured moths; this was not expected, as the subsites were located so close to each other. The subsites were chosen to represent as similar habitats as possible, but with some variation in vegetation and in some abiotic factors (see Material and methods). This means that habitat specificity had no significance for moths, most of which have a large active flight radius. Less than 10 percent of the variation in the results was explained by the subsite.

\section{Discussion and recommendations}

Our results show clearly that the Ryrholm trap $\mathrm{R} / 125$ collected both species and individuals most effectively. Part of this is due to the lamp, a 125W mercury vapour lamp, which has also been shown to be more effective in other connections (see e.g. Mikkola 1972). However, not all of this difference can be explained by the different lamp, because J/125 had the same lamp, but this trap was only slightly better than $J / 160$, the control trap. Especially in the case of beetles, R/125 seemed to be quite superior compared with the other traps and particularly to $\mathbf{J} / 160$. In these light northern conditions, on the other hands, G/200 was the least effective trap in all respects.

Although the Nordic trap designs, J/160W, $\mathrm{J} 125 \mathrm{~W}$ and $\mathrm{R} / 125 \mathrm{~W}$, yielded approximately comparable alpha index values, the driving variables for this index, i.e. the species and individual numbers, differed significantly in favour of the R/ $125 \mathrm{~W}$ trap. This is due to the larger "volumetric sample" of this trap and the fact that the light spreads more effectively upwards to the levels where many species of the group Noctuoidea studied by Taylor and French (1974) fly. However, the larger catches of both species and individuals result in approximately similar alpha index values, at least for moths. This is also true of the different bulbs of the Jalas trap type. Comparisons show that $\mathrm{J} / 125 \mathrm{~W}$ does not necessary lead to higher alpha index values in southern Finland, either (Söderman et al. 1997). The test did show a significant difference between the Nordic traps designs and the G/200W design. This difference may be due to the fact that its wave lengths are not efficient enough at the northern latitudes. The light summer nights have a great influence upon the catches of the different lamp types in northern Finland (Blomberg et al. 1976), which may be reflected in the results obtained at southern and northern latitudes (see the results of Mikkola 1972 and Blomberg et al. 1976). The results from this paired test at Viiksimo (Table 4) could indicate that the difference is of latitudinal (illumination) nature.

Table 2. The whole-season alpha diversities of the studied insect groups caught with four different trap designs (see Material and methods).

\begin{tabular}{lcccc}
\hline Trap design & Hemiptera & Coleoptera & Macrolepidoptera & Microlepidoptera \\
\hline J/160 W & 9.04 & 13.39 & 27.27 & 46.34 \\
R/125 W & 8.24 & 26.49 & 29.74 & 45.66 \\
J/125 W & 8.24 & 13.78 & 28.34 & 45.17 \\
G/200W & 8.74 & 5.42 & 18.11 & 38.98 \\
\hline
\end{tabular}


No remarkable difference in the alpha index of the two trap designs at Lammi has been evident - in fact, G/200W produces even higher alpha index values than $\mathrm{J} / 160 \mathrm{~W}$ in the same habitat. Some differences have been seen in species composition. G/200W appears to attract better geometrid moths, while $\mathrm{J} / 160 \mathrm{~W}$ is better for noctuid moths. In the tropical forests of the Malayan peninsula, G/200W has been shown to attract high species and individual numbers of particularly pyralid moths (Barlow \& Woiwood 1989). The abundant attraction of pyralids, however, may not be due to the trap design itself, because pyralids are common in the tropics.

Practical considerations determine the choice of trap design in most cases. Based on the experience of the Nordic designs, $\mathrm{R} / 125 \mathrm{~W}$ is definitely to be preferred at wind-exposed open sites (coastal and treeless areas) because of its stability and apparently good functionality at northern latitudes. The Jalas trap, on the other hand, is definitely to be preferred at forested sites, because the falling autumn leaves rapidly plugged up the funnel of the Ryrholm trap. The longer the collection period, the greater the problem. Both trap types have been shown to be somewhat inconvenient in Den-

Table 3. Alpha diversities of the different subsites in the intercalibration test with four different light traps.

\begin{tabular}{lcccc}
\hline & \multicolumn{4}{c}{ Subsites } \\
& 1 & 2 & 3 & 4 \\
\hline Macrolepidoptera & 25.86 & 29.34 & 26.79 & 26.25 \\
Microlepidoptera & 46.77 & 45.22 & 45.00 & 44.24 \\
Total moths & 70.83 & 74.31 & 70.73 & 68.67 \\
\hline
\end{tabular}

Table 4. Results of a comparison made with two light traps (see Material and methods for trap types) at Viiksimo, Kuhmo, eastern Central Finland in 1996. $\mathrm{S}=$ species; $\mathrm{N}=$ individuals.

\begin{tabular}{lcc}
\hline & G/200W & J/160W \\
\hline Macrolepidoptera (S) & 40 & 75 \\
Macrolepidoptera (N) & 537 & 2197 \\
Macrolepidoptera (alpha) & 9.99 & 15.01 \\
Microlepidoptera (S) & 51 & 69 \\
Microlepidoptera (N) & 376 & 727 \\
Microlepidoptera (alpha) & 15.91 & 18.71 \\
\hline
\end{tabular}

mark and Lithuania, where they collect too many individuals under the darker illumination conditions during the summer period (even $>50000$ ind./year). This is inconvenient because of the high workload of the persons sorting and identifiying the material. Therefore, a "less efficient" design would be welcomed in these regions. Whether or not $\mathrm{G} / 200 \mathrm{~W}$ is an alternative for these areas cannot be concluded on the basis of the intercalibration test performed here. We therefore recommend that a similiar intercalibration test should be performed further south, e.g. in Rothamsted. Anyway, when the results of different trap types are compared, one should keep in mind the differences mentioned here. In other words, the results of different traps cannot be evaluated as such, but correction coefficients must be used (see Table 1).

Acknowledgements. This intercalibration test was sponsored by the Nordic Monitoring and Data Group subject to the Nordic Council of Ministers. Nils Ryrholm and Ian Woiwood provided us with their special traps, and we were helped in the field work by Aki Laitila and Jouko Juntunen, all of whom we thank warmly. Lauri Kaila, Kauri Mikkola and Nils Ryrholm gave valuable comments on the manuscript, which improved it essentially.

\section{References}

Anonymous 1996: Monthly weather reports of Finland. Meterological Institute 1996.

Barlow, H. S. \& Woiwod, I. P. 1989: Moth diversity in lowland tropical forest in Peninsular Malaysia. - Journal of Tropical Ecology 5: 37-50.

Blomberg, O., Itämies, J. \& Kuusela, K. 1976: Insect catches in a blended and a black light-trap in northern Finland. - Oikos 27: 57-63.

Bruun, H. 1985: Nattfjärilfångst med några olika UVljuskällor. - Notulae Entomologicae 65: 159. (In Swedish.)

Jalas, I. 1960: Eine leichtgebaute, leichttransportable Lichtreuse zum Fangen von Schmetterlingen. - Ann. Entomol. Fennici 26: 44-50.

Jalas, I. 1969: Perhostenkeräilijän opas. — Otava, Helsinki 268 pp. (In Finnish.)

Kempton, R. A. \& Taylor, L. R. 1974: Log-series and lognormal parameters as diversity discriminants for the Lepidoptera. - Journal of Animal Ecology 43: 381399.

Kouki, J. (ed.) 1994: Biodiversity in the Fennoscandian boreal forests: natural variation and its management. - Ann. Zool. Fennici 31: 1, 3-18.

Lammes, T. \& Rinne, V. 1990: Maps of provincial distribution of Finnish Heteroptera. - Entomol. Fennica 1: 
209-220.

Lindroth, C. H. (ed.) 1960: Catalogus Coleopterorum Fennoscandiae et Daniae. - Ent. Sällskapet i Lund, 1-480.

Marttila, O. 1988: $250 \mathrm{~W}$ ja $400 \mathrm{~W}$ elohopealamppujen yöperhosten pyydystystehon vertailu. - Baptria 13: 1-4. (In Finnish.)

Mikkola, K. 1972: Behavioural and electrophysiological responses of night-flying insects, especially Lepidoptera, to near-ultraviolet and visible light. - Ann. Zool. Fennici 9: 225-254.

Nieminen, M. (ed.) 1996: International Moth Monitoring Scheme, proceedings of a seminar, Temanord, 1996: 630, 1-50. - Nordic Council of Ministers.

Ossiannilsson, F. 1984: The Auchenorrhynca (Homoptera) of Fennoscandia and Denmark. - Fauna Entomologica Scandinavica, Vol. 7, part 3.

Söderman, G. (ed.) 1994: Moth Monitoring Scheme. A handbook for field work and data reporting. Environmental Report 8: 1-63. - Environment Data Centre, Helsinki.

Söderman, G. 1996: Alpha-diversity of log-series applied to the Moth Monitoring Scheme. - In: Nieminen, M. (ed.), International Moth Monitoring Scheme, proceedings of a seminar, Temanord, 1996: 630, 1-50.

Söderman, G., Lundsten. K.-E., Leinonen, R. \& Grönholm, L. 1997: Valtakunnallisen yöperhosseurannan 3. vuosiraportti. - Finnish Moth Monitoring Newsletter 3
(1995), Finnish Environment 62: 1-68.

Sokal, R. R. \& Rohlf, F. J. 1995: Biometry. — Freeman, New York. 3rd edition.

Taylor, L. R. \& Brown, E. S. 1972: Effects of light-trap design and illumination on samples of moths in the Kenya highlands. - Bulletin of Entomological Research 62: 91-112.

Taylor, L. R. \& French, R. A. 1974: Rothamsted Insect Survey. Report from the Rothamsted experimental Station for 1973, Part 2, 240-69.

Taylor, L. R., Kempton, R. A. \& Woiwood, I. P. 1976: Diversity statistics and the log-series model. - Journal of Animal Ecology 45: 255-272.

Väisänen, R. 1993: Valtakunnallinen yöperhosseuranta. (Moth monitoring network of light traps estabilished in Finland.) - Baptria 18: 9-11. (In Finnish, abstract in English.)

Williams, C. B. 1948: The Rothamsted light trap. - Proceedings of the Royal Entomological Society in London A, 23, 80-5.

Williams, C. B. 1951: Comparing the efficiency of insect traps. - Bulletin for Entomological Research 42: 513517.

Woiwood, I. \& Riley, A. 1996: Moth diversity and longterm trends. - In: Nieminen, M. (ed.), International Moth Monitoring Scheme, proceedings of a seminar, Temanord, 1996: 630, 1-50. 